ORIGINAL ARTICLE / ARTIGO ORIGINAL

\title{
Investigation of garbage code deaths to improve the quality of cause-of-death in Brazil: results from a pilot study
}

\section{Investigação de óbitos por códigos garbage para melhoria da qualidade de causas de morte no Brasil: resultados de um estudo piloto}

\author{
Raquel Barbosa de Limal (1), Ashley Frederes" (1), Maria Fatima Marinho " (1), \\ Carolina Cândida da Cunha ${ }^{\prime V}$ (D), Tim Adair ${ }^{V}$ (D), Elisabeth Barboza França ${ }^{\mathrm{VI}}$ (i)
}

\begin{abstract}
Introduction: Reliable cause-of-death statistics are an important source of information on trends and differentials in population health. In Brazil, the Mortality Information System is responsible for compiling cause of death (CoD) data. Despite the success in reducing R-codes ill-defined causes of death, other garbage codes (GC), classified as causes that cannot be the underlying CoD, according to the Global Burden of Disease study, remain a challenge. The Ministry of Health $(\mathrm{MoH})$ aims to decrease the proportion of all GCs, and a pilot study tested a comprehensive strategy to investigate GC deaths that occurred in 2015. Methods: The research was conducted in seven Brazilian cities during five months in 2016: two rural cities, one metropolitan area, and four capitals. For all GCs selected, municipal healthcare workers collected information about the terminal disease from hospital records, autopsies, family health teams, and home investigation. The fieldwork was coordinated at Federal level in partnership with State and municipal teams. Results: Out of 1,242 deaths selected, physicians analyzed the information collected and certified the CoD in 1,055 deaths, resulting in $92.6 \%$ of cases having their underlying cause changed to a usable ICD-10 code. Discussion: It is noteworthy the capacity the health teams in the seven cities showed during the implementation of the pilot. Conclusion: After results analysis, the GC investigation protocol was modified, and the implementation scaled up to 60 cities in 2017.
\end{abstract}

Keywords: Cause of death. Death certificate. Mortality information systems. Vital statistics.

'Coordenação Geral de Informações e Análise Epidemiológica, Departamento de Análise de Saúde e Vigilância de Doenças Não Transmissíveis, Secretaria de Vigilância em Saúde, Ministério da Saúde. Brasília (DF) - Brazil.

"Data for Health Initiative, Vital Strategies, New York (NY) - United States.

"'University of São Paulo, São Paulo (SP) - Brazil.

IVResearch Group in Epidemiology and Health Evaluation, Universidade Federal de Minas Gerais, Belo Horizonte (MG) - Brazil.

vMelbourne School of Population and Global Health, University of Melbourne, Melbourne. Victoria (VI) - Australia.

viPublic Health Graduate Program, Universidade Federal de Minas Gerais, Belo Horizonte (MG) - Brazil.

Corresponding author: Raquel Barbosa de Lima. Setor de Rádio e Televisão Norte, 702, Lote D, building P0700, 60 floor, CEP: 70723-040, Brasília, DF, Brazil. E-mail: racblima@gmail.com

Conflict of interests: nothing to declare - Financial support: Funding from Vital Strategies as part of the Bloomberg Philanthropies Data for Health Initiative (Project 23998 Fundep/UFMG). 
RESUMO: Introdução: Estatísticas confiáveis em mortalidade são importante fonte de evidências de tendências e diferenciais na saúde da população. No Brasil, o Sistema de Informação sobre Mortalidade é responsável por compilar dados da causa de morte (CM). Embora tenha havido sucesso na redução de causas mal definidas de morte, ainda há um problema com outros códigos garbage (GC), classificados como causas de morte que não devem ser registradas como básicas, segundo o estudo de Carga Global de Doença. O Ministério da Saúde estabeleceu uma meta para diminuir a proporção de todos os GC e testou em estudo piloto uma estratégia abrangente para investigar as mortes. Métodos: A pesquisa foi realizada em 7 cidades do Brasil durante 4 meses: 2 em áreas rurais, 1 em área metropolitana e 4 em capitais. Os agentes municipais de saúde coletaram informações sobre a doença terminal obtida nos registros hospitalares, autópsias, equipes de saúde da família e investigação domiciliar. O trabalho de campo foi coordenado pelo nível federal, juntamente com as equipes estaduais e municipais. Resultados: Dos 1.242 óbitos selecionados, médicos analisaram as informações coletadas e certificaram a CM em 1.055 óbitos, resultando em $92,6 \%$ dos casos tendo sua causa subjacente alterada para código específico da CID10. Discussão: Destaca-se a capacidade de articulação que as equipes de saúde apresentaram no cumprimento das etapas propostas para o trabalho. Conclusão: Após o estudo piloto, o protocolo de investigação foi modificado e sua implementação foi ampliada para 60 cidades em 2017.

Palavras-chave: Causa de morte. Atestado de óbito. Sistemas de informação. Estatísticas vitais.

\section{BACKGROUND}

Information on mortality is an important source of evidence of trends and differentials in population health. Vital statistics - produced by the legal registration of births and deaths by age, sex and causes - are an excellent source of demographic and epidemiological information on population diseases resulting in mortality. Health systems should rely on good quality information on causes of death for health policymaking to prevent premature mortality and promote population health ${ }^{1}$.

In Brazil, the Mortality Information System (SIM) is responsible for compiling cause-ofdeath data for the whole country. This system has been maintained by the national Ministry of Health (MoH) since 1975, and it reports approximately 1.3 million deaths annually ${ }^{2,3}$. The SIM is decentralized and reported over $95 \%$ of all deaths in the country in 2000-2010. However, the accuracy of cause-of-death data needs improvement. In 2000, $14.3 \%(n=135,749)$ of all deaths were classified as ill-defined causes or R codes, that is, deaths codified as signs, symptoms and other abnormal clinical and laboratory findings, according to chapter 18 of the $10^{\text {th }}$ revision of the International Statistical Classification of Diseases and Related Health Problems $(\text { ICD-10) })^{4}$. These unknown or ill-defined causes of death (IDCD) are useless for public policy. In 2005, the Ministry of Health implemented a strategy to improve cause of death information that included investigation of IDCD, suspected maternal deaths in women of reproductive age, and deaths in infants under 1 year of age. In this strategy, regulations require a local surveillance team in the municipalities and hospitals to investigate ill-defined deaths and detect the true underlying causes of death. In 2010, of 97,314 deaths classified as IDCD, 
$30.3 \%$ were investigated and $65.5 \%$ were reclassified to a more informative cause ${ }^{5}$. Despite the national reduction in this indicator, regional discrepancies remain, being lower in the South and South-East regions and higher in Northern regions ${ }^{6}$.

Despite success in reducing IDCD, Brazil still has a problem with garbage codes (GC). The Global Burden of Disease (GBD) study pioneered this term to describe causes that cannot or should not serve as an underlying cause of death ${ }^{7-9}$. These include R codes for ill-defined causes, conditions that cannot be classified as cause of death such as back pain, intermediate or immediate causes such as heart failure, or insufficiently specified causes such as pneumonia. Using the SIM database, the GBD Study 2015 showed that approximately 33\% of deaths in Brazil were assigned a GC as the cause of death that year, compared with $30 \%$ for all reported causes of death globally ${ }^{8,10,11}$.

In spite of a continuous decline in the percentage of IDCD, particularly in the North and Northeastern regions, the proportion of deaths assigned as other GCs remains the same every year, as the GBD study detected, with similar proportions in all regions ${ }^{2,12}$. According to the $\mathrm{MoH}$ in 2015 , whereas the majority $(56.5 \%)$ of IDCD (chapter 18 ) occur in the decedent's home, over $65 \%$ of GC deaths occurred in hospitals. Regarding age and sex, no differences were found between two code groups with ill-defined causes of death. In both cases, it was more frequent in men, approximately $51 \%$. In addition, most deaths occurred in the age group between 60 years or older (65\%). Finally, although the proportion of ill-defined deaths or R codes is higher in the North and Northeast regions, geographically disaggregated data from the 2015 SIM database showed a high proportion of GC across the whole country ${ }^{2}$.

Around 400,000 GC deaths occur in Brazil each year ${ }^{5}$, producing a significant challenge for the Ministry of Health, which has a history of developing innovative interventions to improve the quality of CoD data. However, until recently, this strategy was not extended to garbage codes from other chapters of the ICD-10 $0^{13-15}$. Through this experience, the strategy used to reduce the proportion of $\mathrm{R}$ codes was adapted and extended to reduce the proportion of garbage codes.

The $\mathrm{MoH}$ developed a structured protocol to investigate deaths initially certified with GC and pilot tested it in seven cities distributed across the five regions of Brazil, each with a different demographic profile, in order to test the efficacy and feasibility of the implementation at national scale. To do so, the first goal was to investigate the possibility of reclassifying underlying CoD originally certified with GC to usable ICD-10 codes in seven cities during a five-month period in 2016. The second goal was to develop and verify a protocol with GC investigation forms to standardize the process in the whole country; this protocol was implemented by the municipal and state public health staff to advise the $\mathrm{MoH}$ prior to national rollout. The third objective was to strengthen physicians' capacity to correctly certify the underlying $\mathrm{CoD}$, to improve the quality of mortality data in the long-term. Thus, the objectives of this pilot study were: (1) to investigate deaths certified with GC to establish more accurate underlying causes of deaths, (2) to examine the feasibility of this approach at national scale, and (3) to qualify physicians for accurate medical certification of cause of death. The final purpose of this pilot study was to develop a feasible strategy to improve the quality of mortality data for more informed health policies, resulting in better allocation of resources based on current and projected burden of disease in Brazil. 


\section{METHODS}

The purpose of this pilot study was to conduct research in municipalities with documented cases of GC deaths that are representative of the diverse communities from each region of Brazil. Given the decentralized form of government, the project was first presented to representatives of the states and municipalities and to the municipal health surveillance teams, in order to obtain consent to participate in this pilot. Seven cities were selected for the pilot study - two rural cities, one city surrounding a metropolitan area, and four capitals. Thus, the study was implemented in all five regions of Brazil: South (Florianópolis), Southeast (Belo Horizonte), Northeast (Caicó and Parnamirim), Midwest (Goiânia and Ceres), and North (Palmas).

In June 2016, the selected municipalities consented to participate in the pilot study. To ensure consistency among the pilot sites, the MoH held inception meetings with each local team (municipality and state) to explain the project goals, define the methodology, and discuss the fieldwork strategy and local team composition. The local surveillance teams were comprised of an array of professionals including nurses, social workers, epidemiologists, statisticians, information technology specialists, lawyers, and physicians. The $\mathrm{MoH}$ and local governments, with advisory support from the Data for the Health Initiative (D4H) team in Brazil, conducted trainings for the local surveillance teams and physicians in the seven pilot cities before fieldwork implementation. Fieldwork commenced on June $1^{\text {st }}, 2016$ with the deadline for completion of all investigations set for November $20^{\text {th }}, 2016$; this timeline was established to allow the evaluation of the pilot study and presentation of results to a national stakeholder meeting in November 2016.

For data collection, selection criteria included deaths occurring between January $1^{\text {st }}$ and December $31^{\text {st }}, 2015$ with an underlying cause of death meeting the garbage code criteria available at that time based on the 2010 GBD study, which classified over four thousand ICD-10 codes as garbage. The 2015 mortality records of residents from the seven pilot cities were analyzed to identify GC deaths.

To streamline data collection for the pilot, the MoH created an intranet website called SVS-Collect. Once cases meeting the criteria were identified, these records were extracted from SIM, uploaded to the SVS-Collect website, and access was provided to the municipal health surveillance teams. Teams were responsible for investigating deaths, uploading the data collected from each case to SVS-Collect and entering the revised underlying cause of death in SIM. The SVS-Collect website served as a tool for monitoring and evaluating the fieldwork progress in each municipality.

All investigations were performed using standardized investigation forms for health services and home interviews. The health service forms were provided by the $\mathrm{MoH}$ and were previously used in routine investigations of Chapter $18 \mathrm{R}$ codes, infant deaths and suspected maternal deaths in women of reproductive age to collect information about the deceased's terminal illness. Fieldwork was coordinated by the National level in partnership with State managers and implemented by the local municipal teams. Surveillance teams collected information from various sources, including the routine autopsy services for natural deaths (SVO), 
Institute of Forensic Medicine (IFM) records for external causes, police station records, Family Healthcare Program records, hospitals records (municipal, state, national and private hospitals), and cause or disease-specific databases, such as the Prevention of Deaths in Traffic Accidents Program, Cancer registries, and communicable diseases databases.

For deaths that occurred at home or when the information obtained from the health services was insufficient for ascertaining the underlying $\mathrm{CoD}$, health professionals conducted structured interviews with surviving relatives or caretakes using a standardized verbal autopsy (VA) form for data collection. The VA interview collects information about the signs and symptoms presented by the decedent before death, and these were observed by family members who lived with the deceased during this period. The VA questionnaire used was based on the Portuguese version of the 2007 WHO instrument adapted by the $\mathrm{MoH}$ for the Brazilian context.

A team of sixty physicians from the seven cities in the investigation protocol reviewed the information collected for each case (Belo Horizonte 4; Caicó 6; Ceres 1; Florianopolis 4; Goiania 1; Palmas 6; Parnamirim 38). Based on available evidence, physicians determined and re-certified the underlying cause of death by filling in a new medical certificate of cause of death. All deaths selected for this study had their underlying cause of death reviewed, before and after investigation activities, by ten coders with significant experience in coding causes of death. Following medical re-certification, the team of coders coded the reclassified underlying $\mathrm{CoD}$, which was uploaded to the SIM database and SVS-Collect website by the surveillance teams.

This study was approved by the Research Ethics Committee of the Federal University of Minas Gerais (CAEE 75555317.0.0000.5149) and developed in accordance with the ethical precepts established by the ordinance no. $466 / 2012$ of the Health National Council.

\section{RESULTS}

Each city manager defined the number of deaths and the place of occurrence for each local team to investigate. Belo Horizonte opted to only investigate deaths of residents occurring in the municipality; the other six cities selected resident deaths regardless of the place of occurrence. The distribution of the cases selected for investigation by municipality is as follows: Belo Horizonte - 271 deaths; Caicó - 97 deaths; Ceres - 30 deaths; Florianopolis 275 deaths; Goiania - 189 deaths; Palmas - 214 deaths; and Parnamirim - 166 deaths (Table 1).

In 2015, there were 6,090 deaths from the seven pilot cities registered in SIM with GC as the underlying cause of death. From this total, 1,242 (20.4\%) cases were selected by the local teams, of which 1,145 (92.2\%) investigations were successfully completed. Of the cases investigated, $53 \%$ were women and $13.1 \%$ were young people aged between 20 and 39 years, $21.1 \%$ were people aged 40 to 59 years, and $61.3 \%$ were people over 60 years. Following the investigations, physicians analyzed the information collected and re-certified the underlying causes of death in 1,055 deaths, which means $92.1 \%$ of cases had their underlying cause changed to a usable ICD-10 code. In $90(7.9 \%)$ cases, the local teams were unable to find 
adequate information to reclassify the cause of death. Additionally, in 78 (7.4\%) cases, the causes of death were changed but remained as other garbage codes. For the deaths selected for the pilot study, the investigations resulted in the reclassification of the underlying cause of death in $85.3 \%$ of cases $(n=977)$, with $14.7 \%$ remaining as garbage codes (Figure 1 ).

Table 1. Distribution of deaths classified as garbage code to investigate the pilot study-Brazil, 2015.

\begin{tabular}{|c|c|c|c|c|c|c|c|c|}
\hline $\begin{array}{l}\text { Residence } \\
\text { occurrence }\end{array}$ & $\begin{array}{c}\text { Belo } \\
\text { Horizonte }\end{array}$ & Caicó & Ceres & Florianópolis & Goiânia & Palmas & Parnamirim & Total \\
\hline $\begin{array}{l}\text { Number of } \\
\text { deaths }\end{array}$ & 271 & 97 & 30 & 275 & 189 & 214 & 166 & 1.242 \\
\hline Goiânia & & & 2 & & 189 & 1 & & 192 \\
\hline Ceres & & & 26 & & & & & 26 \\
\hline Anápolis & & & 1 & & & & & 1 \\
\hline Rialma & & & 1 & & & & & 1 \\
\hline $\begin{array}{l}\text { Belo } \\
\text { Horizonte }\end{array}$ & 271 & & & & & & & 271 \\
\hline Piauí & & & & & & 1 & & 1 \\
\hline Teresina & & & & & & 1 & & 1 \\
\hline Caicó & & 88 & & & & & & 88 \\
\hline Parnamirim & & & & & & & 88 & 88 \\
\hline Natal & & 9 & & & & & 75 & 84 \\
\hline Macaíba & & & & & & & 2 & 2 \\
\hline Canguaretama & & & & & & & 1 & 1 \\
\hline Florianópolis & & & & 275 & & & & 275 \\
\hline São Paulo & & & & & & 1 & & 1 \\
\hline Barretos & & & & & & 1 & & 1 \\
\hline Palmas & & & & & & 205 & & 205 \\
\hline Dianópolis & & & & & & 2 & & 2 \\
\hline Araguaína & & & & & & 1 & & 1 \\
\hline $\begin{array}{l}\text { Dois Irmãos } \\
\text { Do Tocantins }\end{array}$ & & & & & & 1 & & 1 \\
\hline Lajeado & & & & & & 1 & & 1 \\
\hline $\begin{array}{l}\text { Porto } \\
\text { Nacional }\end{array}$ & & & & & & 1 & & 1 \\
\hline
\end{tabular}




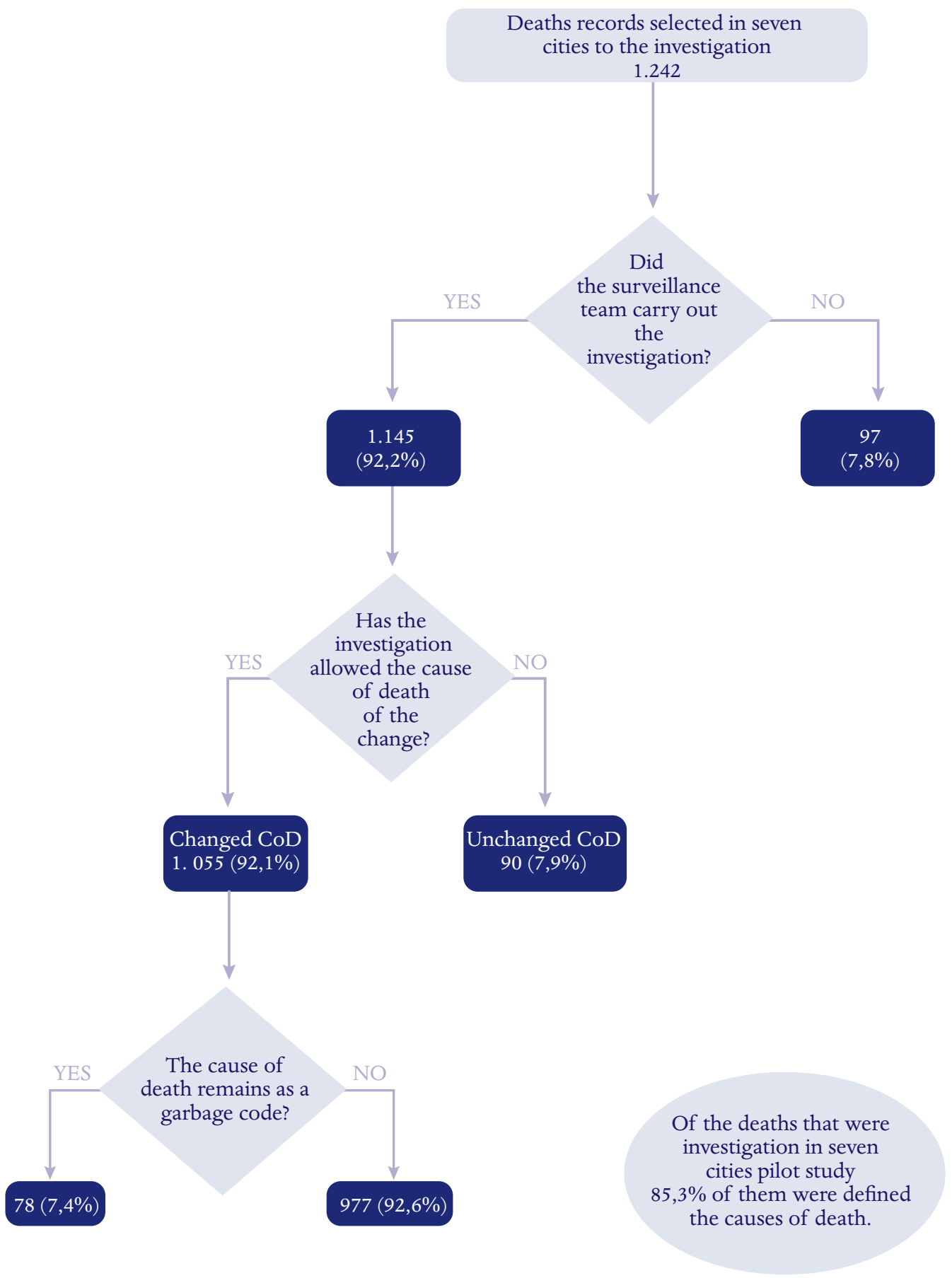

Figure 1. Flowchart of investigation protocol in the seven cities of the pilot study.

Source: Ministério da Saúde. 
The investigations were carried out in multiple sources to re-create the comprehensive medical history of each case. The distribution was as follows: in 744 cases, information was collected from individual's medical records; in 328 cases, from laboratory or other clinical exam results; in 229 cases, from outpatient records; in 214 cases, from medical forensic records; in 169 cases, from VA interviews with surviving family members; and in 104 cases, from routine autopsy service (SVO) records. Police records and news websites were consulted for cases 1 and 2, respectively.

There was a significant redistribution of leading causes of deaths grouped by ICD-10 chapters following the investigation. The leading cause of deaths in the seven cities were in chapter 9 of ICD-10, Diseases of the circulatory system, with a total of 401 cases, of which $44.1 \%$ aggregated in the Cerebrovascular diseases group. External causes (chapter 20) were the second leading cause, comprising $28.7 \%$ of cases $(n=202$ ), of which $14.3 \%$ were classified as motorcycle rider injured in a transport accident. Neoplasia deaths (chapter 2) were the third leading cause with 117 cases, of which $27.3 \%$ of cases were aggregated in the group of malignant neoplasms of the digestive organs. With a total of 98 cases, deaths from endocrine, nutritional and metabolic diseases (chapter 4) were the fourth leading cause, of which $78.6 \%$ were attributed to the diabetes mellitus. Finally, respiratory diseases (chapter 10) were the fifth leading cause (96), with nearly half $(48.9 \%)$ of deaths attributed to influenza and pneumonia. It is noteworthy that one (01) case of maternal death was identified among the deaths investigated. Before investigation, ill-defined causes of deaths were the second leading cause based on identified cases, after investigation, this chapter shifted to the ninth leading cause. Table 2 shows the redistribution of the leading causes of death in the seven cities before and after investigation.

Table 2. Profile of the cause of death before and after investigation in the seven cities, 2015.

\begin{tabular}{|c|c|c|c|c|c|c|}
\hline \multirow{2}{*}{ Chapter (ICD-10) } & \multicolumn{3}{|c|}{ Before } & \multicolumn{3}{|c|}{ After } \\
\hline & Rank & $\mathbf{n}$ & $\%$ & Rank & $\mathbf{n}$ & $\%$ \\
\hline Diseases of the circulatory system & 1 & 420 & 36.7 & 1 & 401 & 35.0 \\
\hline $\begin{array}{l}\text { Sympt. signs and abnormal clin. and laborat. } \\
\text { findings, not classified elsewhere }\end{array}$ & 2 & 200 & 17.5 & 9 & 26 & 2.3 \\
\hline External causes of morbidity and mortality & 3 & 152 & 13.3 & 2 & 202 & 17.6 \\
\hline Neoplasms & 4 & 85 & 7.4 & 3 & 117 & 10.2 \\
\hline Diseases of the genitourinary system & 5 & 81 & 7.1 & 10 & 24 & 2.1 \\
\hline Infectious and parasitic diseases & 6 & 59 & 5.2 & 8 & 29 & 2.5 \\
\hline Diseases of the respiratory system & 7 & 54 & 4.7 & 5 & 96 & 8.4 \\
\hline Diseases of the digestive system & 8 & 42 & 3.7 & 6 & 63 & 5.5 \\
\hline Diseases of the eye and adnexa & 9 & 32 & 2.8 & & & \\
\hline Endocrine, nutritional and metabolic dis. & 10 & 5 & 0.4 & 4 & 98 & 8.6 \\
\hline $\begin{array}{l}\text { Dis. blood and blood-form. organs and cert. } \\
\text { disorders inv. the immune mechanism }\end{array}$ & 11 & 4 & 0.3 & 16 & 3 & 0.3 \\
\hline
\end{tabular}


Table 2. Continuation.

\begin{tabular}{|c|c|c|c|c|c|c|}
\hline \multirow{2}{*}{ Chapter (ICD-10) } & \multicolumn{3}{|c|}{ Before } & \multicolumn{3}{|c|}{ After } \\
\hline & Rank & $\mathbf{n}$ & $\%$ & Rank & $\mathbf{n}$ & $\%$ \\
\hline Dis. of the musculoskeletal sys. con. tissue & 12 & 3 & 0.3 & 13 & 4 & 0.4 \\
\hline Dis. skin and subcutaneous tissue & 12 & 3 & 0.3 & 13 & 4 & 0.3 \\
\hline Mental and behavioral disorders & 14 & 2 & 0.2 & 11 & 17 & 1.5 \\
\hline Certain cond. Origin. in the perinatal & 14 & 2 & 0.2 & 13 & 4 & 0.3 \\
\hline $\begin{array}{l}\text { Congenital malfor., deform. and chromosomal } \\
\text { abnormalities }\end{array}$ & 16 & 1 & 0.1 & 12 & 5 & 0.4 \\
\hline Diseases of the nervous system & & & & 7 & 49 & 3.8 \\
\hline $\begin{array}{l}\text { Injury, poisoning and certain other } \\
\text { consequences of external causes }\end{array}$ & & & & 17 & 1 & 0.1 \\
\hline Pregnancy, childbirth and the puerperium & & & & 17 & 1 & 0.1 \\
\hline
\end{tabular}

For the 1,145 deaths investigated, it is noteworthy the capacity of the local health teams in the seven cities as shown by the rapid implementation and completion of the work and evaluation of results. The stages of implementation were as follows: (1) training of participating municipal health teams; (2) selection of death records; (3) collection of information from relevant sources; (4) review and re-certification of the underlying cause of death by the referring physician; (5) codification of the new underlying cause of death; (6) update of the underlying cause of death in SIM; and (7) upload of the investigation results in the monitoring panel (SVS-Collect). All steps were performed between June 1st and November 20th, 2016, with the presentation of results to the national meeting at end of November.

During the pilot, associated training workshops for physicians were also implemented by the $\mathrm{MoH}$ and local municipal governments, with advisory support from $\mathrm{D} 4 \mathrm{H}$ and the Federal University of Minas Gerais (UFMG). A total of 449 physicians, including pathologists from death verification services (SVO), were trained in medical certification of cause of death and the importance of reliable CoD data for public health policy. The training workshops were held from July $1^{\text {st }}$ to September $15^{\text {th }}$, 2016, with the following number of physicians trained per city: Belo Horizonte - 120; Caicó - 51; Ceres - 18; Florianopolis - 45; Goiania - 18; Parnamirim - 38; and Palmas - 159.

Results from the pilot study were presented at a national meeting in November 2016. The purpose of the meeting was to introduce the protocol and advocate for national adoption of the strategy by key stakeholders, illustrating the potential positive impact on reducing the proportion of deaths initially certified as garbage codes.

The results of the pilot study were used to identify initiatives to strengthen the death investigation process, as well as to improve the quality of CoD data, as described below (Box 1). These include a study protocol that describes the general components of the investigation, including a revised list of GCs for investigation. The GBD 2010 study list used in the pilot was updated to 
the GBD 2015 list of garbage codes and reduced to only 12 groupings of GC. These priority GC account for over $80 \%$ of all GC in the country, and it includes the following: Ill-defined causes (R00-R99, except R95); Unspecified cerebrovascular accident and other sequalae of cerebrovascular (I67.4, I67.9, I69.4, I69.8, I64); Septicemia (A40-A-41); Cardiac insufficiency and unspecified cardiopathies (I50, I51); Essential hypertension (I10); Unspecified neoplasia (C26, C55, C76, C78, C80); Pulmonary embolism (I26); Pneumonia (J15.9, J18); Respiratory insufficiency (J96) and other respiratory disorders(J98); Renal insufficiency (N17, N19); External causes with undetermined intent and unspecified accidents (Y10-Y34, X59); and Unspecified transport accidents and homicides (V89, Y09). Reducing the list of GCs to investigate these priority GCs made the protocol more feasible and effective to apply to 60 cities, after the completion of the pilot study.

Box 1. Positive initiatives proposed after the pilot study in seven cities in Brazil, 2015.

1. Analysis of the deaths investigated in the pilot study with the participation of local certifier physicians and municipal health workers.

2. Development of a modified protocol to investigate deaths classified as garbage codes in 60 cities, including:

2.1. Defining a list of 12 groupings of priority GCs to be investigated in the 60 cities.

2.2. Development of a new form to investigate deaths from natural causes classified as garbage codes for use in hospitals.

2.3. Development of evidence criteria to change the cause of death.

3. Participation of physicians from the pilot study team in the testing of the first version of the medical training mobile phone application, "Certified."

4. Proposal to expand the new strategy for sixty cities in Brazil.

\section{DISCUSSION}

Despite previous considerable efforts to improve the quality of mortality data, the proportion of deaths initially certified as GC remains high, representing over $30 \%$ of all deaths in 2015. The $\mathrm{MoH}$ aims to decrease the proportion of deaths certified with GC by $10 \%$ in ten years. To achieve this goal, the MoH pilot tested a comprehensive strategy to investigate deaths and improve physicians' capacity to medically certify the cause of death through training.

The pilot study showed that there is a wealth of information pertaining to the underlying cause of death available in hospital medical records, primary care medical records, and in autopsy services for natural and external causes. As these cases are concentrated in a limited number of hospitals, this allows for targeted activities within the hospitals and requires fewer resources, bringing thus greater results in a shorter period. For deaths occurring at home or in cases where information from the medical records was insufficient, VA interviews with surviving family members served as complementary sources of information. Although the pilot study was developed in only seven cities, the deaths classified as GC from 
those cities had the same distribution profile as other cities in Brazil, including sex, place of occurrence, and age group. Thus, the whole flow of operations in these seven cities was reproduced as close as possible to the proposal for the posterior major study.

Results of this pilot study set new procedures to improve the feasibility and efficiency of the study protocol. The previous GC list, which contained more than 4,000 ICD-10 codes for investigation was summarized into a more feasible list of $12 \mathrm{GC}$ groupings that are responsible for over $80 \%$ of the total GC in Brazil. The pilot test also showed that the collection of data in hospitals was inadequate, so it was re-formatted to comprise more relevant information, including criteria of evidence, which was used by physicians to change and certify the cause-of-death after investigations.

The new strategy followed targeted efforts to improve CoD data in Brazil through IDCD investigation. The proportion of these causes from chapter 18 of ICD-10 declined from $14.3 \%$ in 2000 to $5.4 \%$ in 2017 . Because ill-defined causes of death predominantly occur at home, the proven strategy for investigating these deaths primarily includes VA interviews with surviving family members and medical record review from hospitals and primary healthcare services. However, deaths occurring at home are dispersed throughout the city, which makes the investigation more difficult and resource-intensive. In contrast, hospitals are the place where deaths are initially certified with garbage codes, so a strategy involving the surveillance teams, hospital boards and the certifying physicians must be adopted in these services.

Consensus for adopting this strategy was reached during the national launch meeting held in November 2016. As such, the $\mathrm{MoH}$ and decentralized state and municipal health departments adopted the revised GC investigation protocol and extended the implementation to 53 cities in Brazil, totaling 60 cities, in 2017.

\section{CONCLUSION}

The MoH continues to review current policies and develop new strategies to improve the quality of mortality data in Brazil, including continued training for physicians in participating hospitals, development of new tools to guide physicians in filling in the medical certificate of cause of death, and capacity building for municipal health surveillance teams to conduct death investigations. Based on the positive outcomes of the pilot study, the Ministry extended activities from 7 cities to 60 cities. Ultimately, the $\mathrm{MoH}$ will extend these activities to the entire country.

\section{REFERENCES}

1. AbouZahr C, Boerma T. Health information systems: the foundations of public health. Bull World Health Organ. 2005;83(8):578-83.

2. Brasil. Ministério da Saúde. Departamento de Informática do SUS. Informações de saúde: mortalidade [Internet]. Brasília; 2018 [citado em
4 fev. 2018]. Disponível em: http://tabnet.datasus. gov.br/cgi/deftohtm.exe?sim/cnv/obt10uf.def

3. Brasil. Ministério da Saúde, Organização PanAmericana da Saúde, Fundação Oswaldo Cruz. A experiência brasileira em sistemas de informação em saúde: volume 1: produção e disseminação de 
informações sobre saúde no Brasil [Internet]. Brasília, DF; 2009 [citado em 2 set. 2019]. Disponível em: http:/ / bvsms.saude.gov.br/bvs/publicacoes/experiencia_ brasileira_sistemas_saude_volume1.pdf

4. Lima EEC, Queiroz BL. A evolução do sistema de registro de mortalidade no Brasil: mudanças no perfil de mortalidade, cobertura do registro de óbitos e as causas mal definidas de morte. Cad. Saúde Pública. 2014;30(8):1721-30. http://dx.doi. org/10.1590/0102-311X00131113

5. Brasil. Ministério da Saúde. Secretaria de Vigilância em Saúde. Departamento de Informação e Análise Epidemiológica. Painel de monitoramento da mortalidade por causas básicas insespecíficas ou incompletas (garbage codes) [Internet]. Brasília, DF; 2018 [citado 4 fev. 2018] Disponível em: http:/ / svs.aids.gov.br/dantps/ centrais-de-conteudos/ paineis-de-monitoramento/mortalidade/ codigos-garbage/

6. Almeida WS, Szwarcwald CL, Frias PG, Souza Júnior PRB, Lima RB, Rabello Neto DL, Cortez Escalante JJ. Captação de óbitos não informados ao Ministério da Saúde: pesquisa de busca ativa de óbitos em municípios brasileiros. Rev Bras Epidemiol. 2017;20(2):200-11. http://dx.doi. org/10.1590/1980-5497201700020002

7. Murray CJL, Lopez AD, editors. The global burden of disease: a comprehensive assessment of mortality and disability from diseases, injuries, and risk factors in 1990 and projected to 2020. Boston: Harvard University Press; 1996.

8. GBD 2013 Mortality and Causes of Death Collaborators. Global, regional, and national agesex specific all-cause and cause-specific mortality for 240 causes of death, 1990-2013: a systematic analysis for the Global Burden of Disease Study 2013. Lancet. 2015;385(9963):117-71. https:/ / doi.org/10.1016/ S0140-6736(14)61682-2

9. Naghavi M, Makela S, Foreman K, O’Brien J, Pourmalek F, Lozano R. Algorithms for enhancing public health utility of national causes-of-death data. Popul Health Metr. 2010 May 10;8:9.

10. GBD 2015 Mortality and Causes of Death Collaborators. Global, regional, and national life expectancy, all-cause mortality, and cause-specific mortality for 249 causes of death, 1980-2015: a systematic analysis for the Global Burden of Disease Study 2015. Lancet. 2016;388(10053):1459-544. https: / / doi.org/10.1016/S0140-6736(16)31012-1

11. GBD 2015 Maternal Mortality Collaborators. Global, regional, and national levels of maternal mortality,
1990-2015: a systematic analysis for the Global Burden of Disease Study 2015. Lancet. 2016;388(10053):1775812. https:/ / doi.org/10.1016/S0140-6736(16)31470-2

12. Brasil. Ministério da saúde. Secretaria de Vigilância em Saúde. Melhoria da qualidade de informação em saúde na percepção de técnicos que colaboram na construção coletiva do livro Saúde Brasil. In: Saúde Brasil 2017: uma análise da situação de saúde e os desafios para o alcance dos objetivos de desenvolvimento sustentável. Brasília, DF; 2018. p. 387-416.

13. França EB, Cunha CC, Vasconcelos AMN, Cortez Escalante JJ, Abreu DX, Lima RB, Morais Neto OL. Investigation of ill-defined causes of death: assessment of a program's performance in a State from the Northeastern region of Brazil. Rev Bras Epidemiol. 2014;17(1):119-34. http:/ / dx.doi. org/10.1590/1415-790X201400010010ENG

14. Brasil. Ministério da Saúde. Secretaria de Vigilância em Saúde. Departamento de Análise de Situação de Saúde. Manual para investigação do óbito com causa mal definida. Brasília, DF; 2008.

15. Ishitani LH, Teixeira RA, Abreu DMX, Paixão LMMM., França EB. Qualidade da informação das estatísticas de mortalidade: códigos garbage declarados como causas de morte em Belo Horizonte, 2011-2013. Rev Bras Epidemiol. 2017;20(supl 1):34-45. http: / / dx.doi.org/10.1590/1980-5497201700050004

Received: 06/14/2019

Final version presented on: 08/01/2019

Accepted: 08/13/2019

Acknowledgments: The authors thank the funding for the study through the Bloomberg Philanthropies, through a grant from Vital Strategies. They also thank the University of Melbourne for providing a scholarship through the Data for Health Initiative for Raquel Barbosa's CRVS Fellowship in Australia, and all the advisory technical support from the Federal University of Minas Gerais.

Author's contribution: Lima RB, Marinho MF and Adair A contributed to the conception and design of the idea, data acquisition, analysis and interpretation, the writing, final approval of the version to be published and are responsible for all aspects of the study. Cunha CC contributed to data interpretation, important critical review of the intellectual content and approval of the final version to be published. Frederes A and França EB contributed to data analysis, writing, important critical review of the intellectual content and approval of the final version to be published. 